\title{
Future of the Euroscientist
}

\author{
David Collingham
}

\section{Labour mobility within the pharmaceutical and biotech sectors in Europe is becoming a crucial issue to both employers and employees.}

EARLIER in this series (see Nature 368, $778 ; 1994)$, I shared my experiences on career development among scientists, gained from over a decade of recruiting experience in the biosciences.

Within the many industrial R\&D establishments in the UK and continental Europe, it is not uncommon to find employees of many nationalities working together at the bench and in management. This leads to the question of how transferable are one's scientific and management skills? Indeed, how transferable is a given individual?

A recent survey by accountants Ernst and Young and the SAGB (Senior Advisory Group on Biotechnology) ${ }^{1}$, relating to Europe's biotechnology industry, shows that the single most important factor influencing investment decisions of biotech companies is the availability of skilled staff in the locations chosen for their operation. They reckon the number of people working in European organisations depending on the application of biotechnology is at least 184,000 , and that the annual rate of increase for small and medium enterprises is $6.5 \%$. Even this pales, however, in the face of a predicted annual rate of $23 \%$ in the USA. Clearly, if these predictions are realised, the mobility of the European scientific labour market is about to be tested.

I recently questioned a number of human resource professionals in the global or European headquarters of world-ranked pharmaceutical or bioscience companies. Their answers varied, but the common theme was of a significant difference between theory and practice. In theory, employees within the EC can rotate jobs or transfer with ease between countries, aided by their laboratories or companies. Nothing could be simpler. In practice all sorts of problems raise their heads.

Location issues can be looked at in two distinct ways: through the eyes of the employer and the employee. For employers - pharmaceutical and biotech R\&D organisations, for example - the choice of a new location is clearly complex and depends upon a myriad of intertwining factors. In Europe, many R\&D centres are set up close to academic research centres; in the biosciences, the favourite locations seem to be Oxford and Cambridge in the UK, Heidelberg and Munich in Germany, and Leiden in The Netherlands, to name just a few. Foreign employ- ing organisations, such as US or Japanese companies, will look at the many economic, scientific and social variables before deciding on a location. There are now in Europe a number of specialist consultancies dedicated to providing information to companies in these situations.

In order to attract senior R\&D managers to a given location, there needs to be not only a favourable scientific climate but also a user-friendly social and economic environment. The tabular material in ref. 2 gives some broad idea of the varying combinations of compensation benefits around Europe, which may influence the employer's decision on the optimal location.

Turning to employees, what are the major factors affecting their job mobility? Much depends on the support given by the employer, of course, for this can have a crucial bearing on the ultimate success of the job placement. Many of the larger organisations have formal schemes in place - trans-Atlantic job swaps, job rotation, overseas secondment, project or task force placement, and so on. Thus a Briton arriving in, say, Glaxo's Italian R\&D organisation in Verona is likely to be given a helping hand with the process of easing himself or herself into the new culture. Nevertheless the cultural gaps can be immense and the person appointed must learn not to expect favoured treatment and to become familiar with the local habits! When in Rome....

\section{Mobility problems}

In our role as recruiters involved in helping to move individuals and their families across country borders, we see successes and some failures. Too often the failures arise from shortsightedness, narrowmindedness and a lack of appreciation of the implications of a family move. Conversely, an otherwise suitable candidate may not fully appreciate the upside of a career-enhancing transnational move, preferring to maintain the status quo rather than risk a major change.

A few years ago, we conducted a short survey of European biotechnology companies, the results of which showed a remarkably xenophobic attitude to labour mobility. Nowadays attitudes are changing and today's scientists and R\&D managers are expected to be mobile, adaptable and flexible. I recently heard it remarked that the common language of science is broken English, a reflection not on educational standards but on the ever-increasing panoply of nationalities found in the modern research laboratory.

The scenario of a Swiss-based pharmaceutical clinical research department moving en bloc to Strasbourg or south-east England is a reality and there may be more examples to follow. This means that the scientist who actively manages his/her career may need to show an increasing adaptability and flexibility to the possibilities of new cultural and geographical changes in job.

So for those readers contemplating a major move of this kind, there are a few hints and tips that will help career advancement and successful relocation:

Is the job right? Are your motives for moving the correct ones?

What are the career prospects? Is there a danger of being 'stuck out on a limb'? How easy will it be reestablish yourself in your home country?

How well will you and your family adapt to your host country? Key factors include ability or need for spouse to work (for example, a Green Card is necessary in the USA), social integration within the host country, ability to learn the host language, and the extent to which your education ambitions for children can be met by the local system.

- Local economic factors. How high are income taxation and other taxes? How does the cost of living compare with the home country? What is the availability of tax incentives (for example, in The Netherlands). What are pension arrangements like?

- Frustration factors that need to be taken into account include local bureaucracy, and difficulty in obtaining housing and essential items such as telephones.

- What are communications like from host country to home country? What is the distance and ease of travel to relatives and friends?

David Collingham is Chairman and Managing Partner of Ruston Poole International, founder member of Global Partners, a worldwide executive search network specialising in healthcare and biosciences. Ruston Poole International is based at 11/12 Buckingham Gate, London SW1E 6LB.

\footnotetext{
1. Biotechnology's Economic Impact in Europe (Ernst \& Young/SAGB, 1994).

2. Pay and Benefits for Staff in Europe (Collingham, D. P. \& Grindley, J. Genetic Engineering News, 14; April 1994).
} 